\title{
Entre dizeres e pensares de Freire e Bakhtin: uma análise da constituição dialógica do dizer do aluno na produção textual
}

\author{
Joseilda Alves de Oliveira (UERN)* \\ https://orcid.org/0000-0003-1403-0342 \\ Nara Karolina de Oliveira Silva (UERN) ${ }^{* *}$ \\ https://orcid.org/0000-0001-5306-4161 \\ José Cezinaldo Rocha Bessa (UERN) ${ }^{* * *}$ \\ https://orcid.org/0000-0003-4655-6832
}

\section{Resumo:}

Este trabalho tem como objetivo refletir sobre o acontecimento da aula de língua portuguesa, focalizando como a mediação do professor e as vivências dialógicas propiciam um evento de interlocução professor-aluno autêntico e efetivo no espaço da aula de produção textual e colaboram com a constituição do ser/sujeito produtor de texto. 0 trabalho assume um diálogo teórico com orientações das teorias educacionais de Freire e contribuições da filosofia da linguagem de Bakhtin. 0 trabalho se ancora também em reflexões de estudiosos que abordam a produção de textos em aulas de língua portuguesa. 0 exercício de análise, de natureza interpretativa, compreende o exame de relações de interação entre professor e aluno durante uma atividade de produção de textos em aulas de língua portuguesa do ensino médio. A análise realizada aponta que a postura interativa e dialógica da professora durante o processo de escrita/reescrita e nas fases que antecederam esse processo contribuiu para o progresso do aluno em relação ao domínio do gênero discursivo solicitado. A análise aponta ainda que, quando há interação entre professor-aluno, o processo de ensino e aprendizagem tende a ser mais produtivo e as relações dialógicas podem influenciar significativamente na constituição do ser sujeito/produtor de textos.

Palavras-chave: Relações dialógicas. Produção de textos. Ensino Médio.

* Doutoranda em Letras pelo Programa de Pós-Graduação em Letras da Universidade do Estado do Rio Grande do Norte/Campus de Pau dos Ferros. Mestre em Ensino pelo Programa de Pós-Graduação em Ensino da Universidade do Estado do Rio Grande do Norte/Campus de Pau dos Ferros. E-mail: joshitalo@ gmail.com

** Mestranda em Letras pelo Programa de Pós-Graduação em Letras da Universidade do Estado do Rio Grande do Norte/Campus de Pau dos Ferros. E-mail: narakarolina25@gmail.com

*** Docente do Programa de Pós-Graduação em Ensino e do Programa de Pós-Graduação em Letras da Universidade do Estado do Rio Grande do Norte/Campus de Pau dos Ferros. E-mail: cezinaldobessauern@gmail.com 


\title{
Abstract:
}

\section{Among sayings and thinkings by Freire and Bakhtin: an analysis of the dialogical constitution from student's sayings when writing text}

\begin{abstract}
This work aims at reflecting on how Portuguese Language occurs, focusing on how the teacher's mediation and dialogical experiences can promote an interlocutive, authentic and effective event in the classroom when students are supposed to write texts, and how this environment can positively collaborate to students competence as a text-writer. The work assumes a theoretical dialog guided by Paulo Freire's contributions about education and language philosophical comprehension developed by Mikhail Bakhtin. This way, the work is also anchored on reflections by scholars that lead with text production in Portuguese teaching. Methodological analysis goes on a reflective perspective that understands the exam of interaction between teacher and students during the text writing activity in Portuguese classes in high school. The analysis points out that teacher's interactive and dialogical posture while students are writing and even in the previous moments, when the teacher prepares students to write, contribute to a positive student's progression in what is concerned to the kind of discursive genre they are supposed to handle when required. The analysis also show that when teachers and students strongly interact, teaching process undertake in a very productive way, so that dialogical relations can highly influence in the constitution of a subject/text-writer.
\end{abstract}

Keywords: Dialogical relation. Text production. High School.

\section{Palavras introdutórias}

A vida é dialógica por natureza. Viver significa participar do diálogo: interrogar, ouvir, responder, concordar, etc. (BAKHTIN, 2011, $p$. 348).

Tomando como mote as palavras do filósofo da linguagem Mikhail Bakhtin, entendemos que nenhum ser se constitui sozinho, no isolamento, fechado para a escuta de outrem. Essas palavras do filósofo da linguagem acentuam que somos seres inevitavelmente dependentes da presença do outro, de seus dizeres, de seus gestos, de seus olhares, de suas (re)ações. Pensando ainda com e a partir de Bakhtin, podemos dizer que, sem um processo de intercâmbio social, mediado pela linguagem, não nos constituiríamos como seres sociais que somos; permaneceríamos, pois, sujeitos sem consciência, sem capacidade de significar, de produzir sentidos.

Segundo o ponto de vista dialógico proposto por Bakhtin, os diálogos que travamos com o outro e a nossa inscrição sociohistórica marcam o nosso nascimento social ${ }^{1}$ e nos constituem como seres/sujeitos (in)acabados que somos. Conceber o diálogo, a interação e o (in)acabamento como pilares para a

1 Conforme Miotello e Moura (2016), o nascimento social sucede o nascimento biológico. De acordo com essa compreensão, somente a partir da interação com o outro é que o indivíduo se constitui ser de linguagem, passa a ter uma consciência e a fazer parte do existir-evento. 
constituição do ser/sujeito nos impulsiona a refletir acerca da nossa prática em sala de aula de língua portuguesa enquanto sujeitos situados socialmente e enquanto construtores de conhecimentos. Neste trabalho, nossas reflexões se voltam ao contexto da sala de aula, partindo de uma inquietação que é pensar que a sala de aula de língua portuguesa pode ser espaço de constituição de subjetividade (MENDONÇA, 2019), de encontros/interações, de trocas de experiências, de compartilhamento de vivências singulares entre alunos e professor.

Tal inquietação nos mobiliza a enxergar para além de uma dicotomia, que, muitas vezes, sustenta, de um lado, os professores como sujeitos acabados, detentores de todo conhecimento, com dificuldades de refletirem sobre suas práticas e de reconhecer o aluno como seu outro com o qual pode aprender e vir a ser outro, e, de outro lado, os alunos, tomados como sujeitos sem voz, sem experiências, sem potencial de também ensinar. Essa ordem de inquietação nos faz lembrar e nos aproximar do pensamento de Freire (1996, p. 23), quando diz que o "sujeito que ensina é também o que aprende e vice-versa".

Considerando, pois, as possibilidades de interlocução entre as ideias de Freire e o pensamento de Bakhtin, desenvolvemos este trabalho tomando como pontos de ancoragens centrais concepções desses estudiosos sobre a interação e o inacabamento na constituição do ser/sujeito. Assumimos mais especificamente as posições de Freire (1986, 1996, 2014) e de Bakhtin (2011, $2016,2017)$ que nos permitem pensar o acontecimento da vida, que, para esses pensadores, é constituída por sujeitos dialógicos, responsivos e inconclusos.

Partindo desses pontos de vista e dessas ancoragens, objetivamos aqui refletir sobre o acontecimento da aula de língua portuguesa, focalizando mais especificamente como a mediação do professor e as vivências dialógicas propiciam um evento de interlocução professor-aluno autêntico e efetivo no espaço da aula de produção textual e colaboram com a constituição do ser/sujeito produtor de texto. Buscamos dar conta desse empreendimento investigativo com base na análise de relações de interação entre professor e aluno durante uma atividade de intervenção voltado para a produção de textos em aulas de língua portuguesa do ensino médio.

Acreditamos que este estudo pode contribuir com a reflexão sobre as práticas de linguagem em sala de aula de língua materna, posto que permite colocar em questionamento situações de produção de textos em que observamos, por exemplo, a pouca participação dos alunos nas aulas e a indisposição deles para escrever e, sobretudo, para reescrever os textos, quando solicitados. Em última instância, o estudo possibilita nos interrogarmos sobre a (im)possibilidade de vivência de uma situação de interlocução autêntica entre sujeitos que falam e se escutam, em um contexto em que, claramente, "a transmissão de conhecimentos deixou de ser a função da escola” (GERALDI, 2017, p. 492).

\section{Entre dizeres e pensares de Freire e Bakhtin: reflexões sobre o educador, o educando e a construção do saber na vivência dialógica}

Fizemos um jogo sobre saberes e empatamos dez a dez. Eu sabia dez coisas que vocês não sabiam e vocês sabiam dez coisas que eu não sabia. Pensem sobre isto. (FREIRE, 2000, p. 48-49). 
Com base nesses dizeres de Freire (2000), conjecturamos que são muitas as necessidades e possibilidades de um percurso educacional que seja capaz de dialogar melhor com o mundo, com as experiências de educadores e educandos ${ }^{2}$, com as expectativas de educadores, com as curiosidades dos educandos, para que o processo de construção do saber, no espaço de sala de aula, possa ser compreendido na relação de escuta e de vivência dialógica com o outro.

Os processos de ensinar e aprender são, como ponderam Freire (2000), construídos de idas e vindas, das trocas de experiências e das relações entre as pessoas. Tais processos não acontecem de forma isolada; eles pressupõem sujeitos, interações mediadas pelas palavras. Como conceber esses processos no espaço escolar? Com base em Freire e em Bakhtin, podemos conceber que, como educadores, somos desafiados a nos interrogar sobre muitas de nossas posturas, escolhas, práticas e atos, caso nosso propósito seja a vivência de uma construção coletiva e dialógica do conhecimento.

No encontro com as ideias desses dois pensadores, podemos, pois, formular, mas sem pretensões de esgotar e de construir respostas fechadas, algumas perguntas: quem é o outro com o qual interagimos em nossas aulas? Quais são as atitudes que pretendemos provocar, em nossos alunos, com os nossos dizeres? 0 que eles nos respondem? Que sujeitos alunos estamos formando? Será que estamos, de fato, dialogando, na sala de aula, com as experiências trazidas pelos educandos, fazendo-os reconstruir seu espaço dentro e fora da escola? Será que

2 Esclarecemos que, ao longo desse texto, faremos uso dos termos educador educando sempre que nos reportarmos às ideias de Freire. Nos demais contextos, fazemos uso dos termos professor e aluno, respectivamente. estamos conseguindo ler os não-ditos e os silêncios de nossos alunos?

Embora Bakhtin não tenha se ocupado de discorrer especificamente sobre a educação e as relações que ocorrem no espaço de sala de aula, considerações resultantes das reflexões do Círculo sobre a construção do conhecimento e o funcionamento da linguagem concebidos em sua dimensão sociológica têm muito a contribuir sobre o ambiente de ensino/aprendizagem, a sala de aula, no tocante à relação professor-aluno e o diálogo que constrói essa relação. Diálogo entendido aqui não como algo convencional, como interação face-a-face apenas, mas em sentido amplo, como elemento constitutivo do funcionamento da linguagem, da comunicação discursiva (BAKHTIN, 2016).

Diferentemente de Bakhtin, Freire $(2000,1996)$ se volta para a reflexão sobre a esfera educativa. Desse horizonte, confere uma importância muito forte à função do diálogo nas relações de construção do Ser e do saber. É preciso dizer que as reflexões de Freire (1996) permitem pensar a defesa das trocas dialógicas para além das situações pedagógico-metodológicas, compreendendo também a formação e construção do Ser também fora dos espaços escolares, na vida social e para atuação política na vida social.

As proposições apontadas por Freire (1996) sobre a importância do diálogo como troca de experiências, vivências, culturas e ponte para idas e vindas de saberes em construção nos faz (re)pensar a prática de sala de aula (e no nosso caso, da aula de língua portuguesa) de uma maneira mais instigante e produtiva, uma vez que concebida de maneira mais dialógica e interativa, tendo em consideração que, como sustenta Freire (2014, p. 109), o diálogo "é o encontro em que se solidarizam o refletir e o agir 
de seus sujeitos endereçados ao mundo a ser transformado e humanizado".

Nessa linha de compreensão, quando transpostas para a sala de aula, as proposições de Freire (2014) sobre o diálogo nos possibilitam reconstruir, a partir do encontro com o outro, a significação mediada pela linguagem, o valor dos enunciados e as formas de relação entre os sujeitos no processo de ensino/aprendizagem. Para Freire (2014, p. 109), esse diálogo constituinte de si e do outro "[...] não pode reduzir-se a um ato de depositar ideias de um sujeito no outro, nem tampouco tornar-se simples troca de ideias a serem consumidas pelos permutantes". De acordo com esse estudioso, trata-se, na verdade, de uma relação indissociável de idas e vindas de trocas com as palavras do outro, já que a própria existência dos Seres que, mediados pela linguagem, nessas trocas se constroem, está em constante movimento de transformação.

Consoante a essa perspectiva, Bakhtin (2016) aponta que nos constituímos nas relações de interação que estabelecemos com a palavra, o enunciado de outrem, pois, em cada círculo social, seja em épocas diferentes ou em espaços diferentes, "sempre existem enunciados investidos de autoridade que dão o tom, como as obras de arte, ciência, jornalismo político, nas quais as pessoas se baseiam, as quais elas citam, imitam, seguem" (p. 54). Esses dizeres do filósofo da linguagem russo reforçam a importância da palavra do professor e das trocas interativas na constituição do aluno como sujeito em processo de formação/construção, como ser inacabado, em contínuo devir, como alguém que também tem algo a dizer.

0 que podemos, então, tirar de proveito dessa interlocução entre dizeres e pensares de Bakhtin e Freire, para pensarmos as relações que permeiam o processo de ensino e aprendizagem? Parece-nos evidente que esses pensadores nos permitem olhar com mais amorosidade a ideia de que os sujeitos envolvidos na cena educativa estejam mais abertos à escuta do outro e possam vivenciar de forma mais efetiva uma experiência de construção dialógica de conhecimentos. Os ganhos de uma prática assim concebida podem ser vislumbrados nas seguintes palavras de Freire (1996, p. 136): “o sujeito que se abre ao mundo e aos outros inaugura com seu gesto a relação dialógica em que se confirma como inquietação e curiosidade, como inconclusão em permanente movimento na História".

$\mathrm{Na}$ compreensão assumida, a consideração da abertura para a escuta do outro e de sua palavra, da aceitação da condição de professor e alunos como sujeitos (in)acabados que ensinam e aprendem um com o outro, bem como da vivência da experiência dialógica nas relações no espaço de sala de aula constituem um acontecimento singular e transformador das práticas de linguagem em aulas de língua portuguesa e do processo de ensino/aprendizagem e da construção de conhecimentos.

Acreditamos, pois, que essa abertura para a relação dialógica na sala de aula pode estar pautada numa prática docente que fomente a curiosidade, a criticidade e a capacidade de significar e ressignificar o mundo por meio do uso da palavra. Não por acaso, Geraldi (2003/2004, p. 51), relacionando ideias de Bakhtin e Freire, nos diz que "[...] no diálogo encontra-se a estratégia de construção social [...] e na linguagem, o lugar do encontro e desencontro dos homens. Significar o mundo [...]". Assim, faz-se necessário pensar/refletir sobre os possíveis mundos que o professor precisa considerar para fazer do espaço de sala de aula um ambiente instigante e sedutor, para que possamos ter 
aprendizagens significativas e mobilizadoras para a ação e a transformação social.

\section{A produção textual escrita como atividade dialógica}

"[...] lembremos que um texto é o produto de uma atividade discursiva onde alguém diz algo a alguém" (GERALDI, 2013, p. 98, grifo do autor).

Reportando-nos às palavras de Geraldi (2013), compreendemos que a produção textual escrita como atividade dialógica pressupõe um exercício de interlocução entre sujeitos que dialogam, comungam ideias/pensamentos, compartilham experiências, constroem conhecimentos e agem uns sobre os outros. Nesse sentido, o trabalho com a produção textual compreende uma prática social e interativa, que leva em conta projetos de dizer, interlocutores, esfera discursiva, veículo de circulação, dentre outros aspectos.

Para Antunes (2009, p. 20), o trabalho com a linguagem na escola esteve por muito tempo pautado numa visão reducionista, em que "[...] os efeitos de sentido pretendidos pelos interlocutores e as finalidades comunicativas presumidas para os eventos verbais quase nada importavam". Podemos dizer que, na visão da autora, o trabalho com o texto em sala de aula desconsiderava a atividade de escrita como uma prática situada, em que se viabilizaria uma situação autêntica de interlocução entre sujeitos que têm algo a dizer a alguém, afinal "nenhum texto acontece sem uma finalidade qualquer, sem que se pretenda cumprir com ele determinado objetivo" (ANTUNES, 2010, p. 69).

Com base no que afirmam estudiosos como Antunes (2010), Geraldi (2012, 2013, 2015), Rojo e Barbosa (2015) e Lopes-Rossi (2011), dentre outros, podemos assumir que o tratamento dispensado à produção de textos nas aulas de língua portuguesa vem apresentando algumas alterações positivas. As palavras de Geraldi (2013, p. 105) ratificam esse entendimento: "[...] o trabalho com a linguagem na escola vem se caracterizando cada vez mais pela presença do texto, quer enquanto objeto de leituras, quer enquanto objeto de produção", o que indica uma perspectiva de se tomar a linguagem, o texto e a produção textual como atividade sociocomunicativa.

A defesa de estudiosos como como Antunes (2010) e Geraldi (2013) é que a prática de produção de textos ganhe cada vez mais espaço na sala de aula e esteja orientada no sentido de fazer com que os alunos percebam os textos que produzem não como um produto, mas como um processo resultante de uma atividade dialógica, de construção colaborativa e de negociação de sentidos. Entendida dessa forma, a produção textual passa a ser encarada como atividade interlocutiva (GERALDI, 2013, 2015), em que o aluno é levado a compreender a presença do outro, do interlocutor na sua escrita, e a perceber que o que ele escreve expressa "[...] efeitos de sentidos discursivos, ecos ideológicos, vozes e apreciações de valor que o sujeito do discurso faz por meio dos enunciados/textos" (ROJO; BARBOSA, 2015, p. 42).

Nessa perspectiva aqui exposta, o trabalho de levar o aluno a compreender a construção do texto como uma atividade interlocutiva abarca, portanto, muito mais que explorar a mera organização de palavras e frases gramaticalmente corretas, implica, pois, considerar, conforme apontam Geraldi (2013, 2015) e Moretto (2013), o ato de escrever como um momento de dialogar com o texto, de refletir sobre ele, de fazer aprimoramentos. Com isso, compreendemos que a 
atitude do professor diante das produções dos alunos deve considerar, dentre outros aspectos, a forma do dizer, a singularidade do sujeito e o querer dizer expresso na sua escrita, visto que

[...] a criatividade posta em funcionamento na produção do texto exige articulações entre situação, relação entre interlocutores, temática, estilo do gênero e estilo próprio, o querer dizer do locutor, suas vinculações e suas rejeições aos sistemas entrecruzados de referências com as quais compreendemos o mundo, as pessoas e suas relações (GERALDI, 2015, p.115).

Cremos, assim, que devemos pautar o desenvolvimento da prática da produção escrita na escola voltado ao propósito de levar o aluno a refletir sobre as escolhas linguísticas mobilizadas em suas (re)elaborações textuais. Um trabalho assim concebido implica uma atuação do professor como agente mediador que coopera com a escrita e a reescrita dos textos do aluno, com vistas ao aprimoramento do dizer em conformidade com as finalidades comunicativas pretendidas e interlocutores previstos.

Há que consideramos, por fim, que ensinar a escrever exige que o professor saiba que a produção de texto começa antes das atividades propostas em sala de aula e que a prática de produzir textos se faz com a mediação do professor (GERALDI, 2015), pois, bem sabemos, que o aluno carece que o professor o auxilie no processo de conscientização de sua própria fala, do seu projeto de dizer, como condição para uma atuação verbal bem-sucedida.

\section{Metodologia}

0 presente trabalho insere-se no domínio de uma epistemologia das ciências humanas como depreendida das reflexões de Bakhtin (2016, 2017). Esse modo de compreender a pesquisa em ciências humanas, que assumimos em nossas investigações no domínio dos estudos da linguagem, permite pensar que o pesquisador lida, afinal, com textos, que se constituem um objeto falante (AMORIM, 2016). 0 trabalho do pesquisador, nesse sentido concebido por Bakhtin, é construir compreensões, as mais profundas possíveis, mediante o exercício de cotejar textos, observando regularidades e singularidades.

Por esse viés assumido, nosso estudo tem uma natureza interpretativa. Além disso, nosso estudo pode ser caracterizado como de abordagem qualitativa, visto que buscamos "compreender e interpretar os sentidos e dizer 'coisas significativas e substanciais"' sobre o objeto de pesquisa (BESSA, 2016, p. 47 , grifo do autor) sem manifestar preocupação com quantificações e generalizações.

0 contexto de pesquisa do qual foi recortado o material de análise, neste trabalho, compreende aulas de língua portuguesa, mais precisamente de produção de textos, de uma turma de primeiro ano do ensino médio de uma escola pública. Neste estudo, nossa análise se voltou ao exame de uma carta de leitor, em diferentes momentos do processo de escrita, produzida por um aluno participante de um projeto de intervenção realizado como parte de uma pesquisa de Mestrado em Ensino pelo Programa de Pós-Graduação em Ensino, da Universidade do Estado do Rio Grande do Norte.

No projeto de intervenção realizado, os alunos foram solicitados a produzirem o gênero discursivo carta do leitor sobre a temática da cobrança de mensalidades nas universidades públicas brasileiras como exercício de postura responsiva ao editorial de jornal, entendido como gênero do discurso, que foi trabalhado em atividades de leitura desenvolvidas em momento anterior do projeto. 
Para uma melhor compreensão dos momentos vivenciados durante a realização do projeto, e consequentemente, de como foram as atividades envolvidas no processo de produção escrita do aluno, apresentamos, no quadro abaixo, uma síntese que contempla as etapas e as atividades do trabalho de intervenção desenvolvido.

Quadro 01- Resumo descritivo das etapas e atividades do projeto

\begin{tabular}{|c|l|}
\hline ETAPAS & \multicolumn{1}{c|}{ RESUMO DESCRITIVO DAS ATIVIDADES DO PROJETO } \\
\hline 01 & Realização de uma contextualização sobre texto, leitura e escrita \\
\hline 02 & $\begin{array}{l}\text { Apresentação da temática (sugerida pelos alunos) e da proposta de trabalho com os } \\
\text { gêneros discursivos editorial e carta do leitor }\end{array}$ \\
\hline 03 & $\begin{array}{l}\text { Leitura dos editoriais e discussão sobre como a temática era abordada nos textos; } \\
\text { discussões relacionadas às características do gênero; análise coletiva dos recursos } \\
\text { linguísticos utilizados; debate sobre o tema, a tese e os argumentos dos textos explorados. }\end{array}$ \\
\hline 04 & $\begin{array}{l}\text { Leituradascartasdoleitor;análise coletivados recursos linguísticos utilizados; debate sobre } \\
\text { a tese defendida e os argumentos construídos pelo produtor das cartas exploradas. }\end{array}$ \\
\hline 05 & $\begin{array}{l}\text { Visita ao espaço de produção do editorial (Jornal Patosonline); conversa com o } \\
\text { editorialista do jornal; visita ao Museu do Jornalismo da cidade. }\end{array}$ \\
\hline 06 & $\begin{array}{l}\text { Produção escrita sobre o tema discutido: cobrança de mensalidades nas universidades } \\
\text { públicas brasileiras. }\end{array}$ \\
\hline 07 & $\begin{array}{l}\text { Análise das produções dos alunos pela professora; análise do próprio texto, pelos alunos, } \\
\text { com as orientações apresentadas pela professora. }\end{array}$ \\
\hline 09 & $\begin{array}{l}\text { Reescrita individual dos textos pelos alunos. } \\
\text { voltada para as turmas de 30 ano; exposição dos textos para a comunidade escolar e para } \\
\text { os pais }\end{array}$ \\
\hline
\end{tabular}

Fonte: Dados da pesquisa de Oliveira (2019)

Cumpre salientar que os diálogos estabelecidos com os gêneros editorial e carta do leitor e com seus espaços de produção e de circulação durante as etapas que antecederam a atividade de produção escrita propriamente foram pensados com a finalidade de estimular a produção textual como uma atividade processual e prática social. Além disso, destacamos que as atividades realiza- das após o ato de escrita do texto sugerem o ato responsável e responsivo dos alunos que participaram do projeto, no sentido de compreenderem que a temática deveria ser apresentada/discutida para/com toda comunidade escolar, sobretudo, para/com alunos das turmas de $3^{\circ}$ ano, visto que muitos desses alunos almejavam vagas nas universidades públicas. 
Embora possamos considerar uma dimensão processual e interações efetivas entre aluno e professor desde as atividades da primeira etapa, a análise que apresentamos aqui se concentra de modo mais específico no exame das versões do texto do aluno, sem, contudo, deixar de considerar registros de notas de campo que fizeram parte da referida pesquisa.

A escolha pelo texto de um aluno em específico se justifica do ponto de vista da ancoragem teórica nos estudos de Bakhtin, para cujos pressupostos teóricos todo enunciado é único e singular, bem como do ponto de vista de conceber uma análise que explore a produção de textos como atividade processual. Nesse sentido, assumimos o texto recortado para exame como um exemplar de enunciado, em diferentes versões, que manifesta marcas singulares e únicas, as quais nos permitem compreender de modo mais profundo as relações interativas constitutivas dos sujeitos envolvidos na situação de interlocução vivenciada.

Ressaltamos ainda que, na nossa análise, consideramos a carta do leitor como enunciado em seu todo concreto e singular, ainda que, na sistematização que fazemos a seguir, optemos por segmentar as partes do texto, com vistas a realçar aspectos que se mostraram mais significativos e substanciais para os propósitos desse estudo.

\section{As interlocuções na atividade de produção de textos e a constituição do sujeito/aluno produtor de textos}

Nesta seção, centraremos na análise de como a mediação do professora/pesquisa- dora e as vivências dialógicas propiciaram um evento de interlocução professor-aluno autêntico e efetivo no espaço da aula de produção textual e colaboram com a constituição do ser/sujeito produtor de texto. Para darmos conta desse propósito, examinamos relações de interação entre professor e aluno durante uma atividade de produção de textos em aulas de língua portuguesa do primeiro ano do ensino médio. Interessa-nos demonstrar como a postura dialógica da professora/pesquisadora pode ter contribuído para a mudança de postura do aluno em relação às atividades em sala de aula e enquanto ser crítico e produtor de textos.

Como já anunciado, na seção de metodologia, nos concentraremos no exame do gênero carta do leitor produzido por um dos alunos da turma investigada, uma vez que nos interessa focalizar as interlocuções entre aluno e professora/pesquisadora considerando as três versões da produção escrita. Levando em conta que o gênero carta de leitor compreende, conforme Bezerra (2010), três elementos (a seção de contato; o núcleo da carta, composto de introdução, desenvolvimento e conclusão; e a seção de despedida), sistematizamos nossa análise considerando a segmentação do texto em três partes: uma primeira, em que consideramos a seção de contato e a introdução; uma segunda, em que focalizamos o desenvolvimento; e uma terceira, em que contemplamos a conclusão e a despedida.

Com base nesses direcionamentos, passemos à análise, trazendo, inicialmente, o exame da seção de contato e da introdução da carta do leitor produzida pelo aluno nas três versões: 
Quadro 02- seção de contato e introdução da carta do leitor em cada versão da escrita

\begin{tabular}{|c|c|}
\hline & unikeraideade \\
\hline $\begin{array}{l}\text { Primeira } \\
\text { versão }\end{array}$ & $\begin{array}{l}\text { Preando as peasoas Rovar Razer uma } \\
\text { Raculdade, ninguém drueria kagar uma taxa } \\
\text { de mensalidade. }\end{array}$ \\
\hline $\begin{array}{l}\text { Segunda } \\
\text { versão }\end{array}$ & 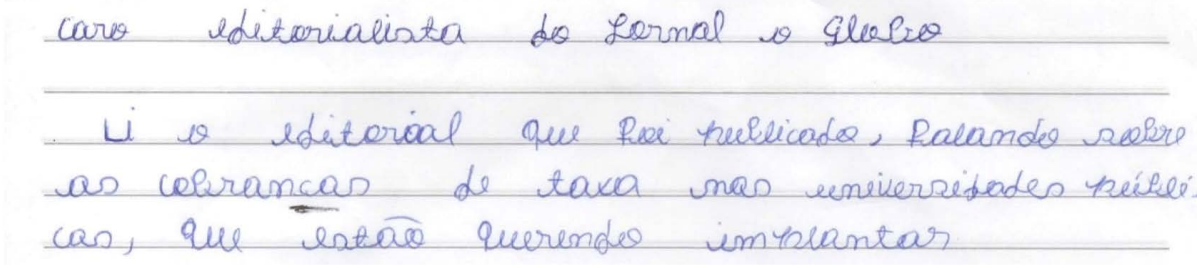 \\
\hline $\begin{array}{l}\text { Terceira } \\
\text { versão }\end{array}$ & 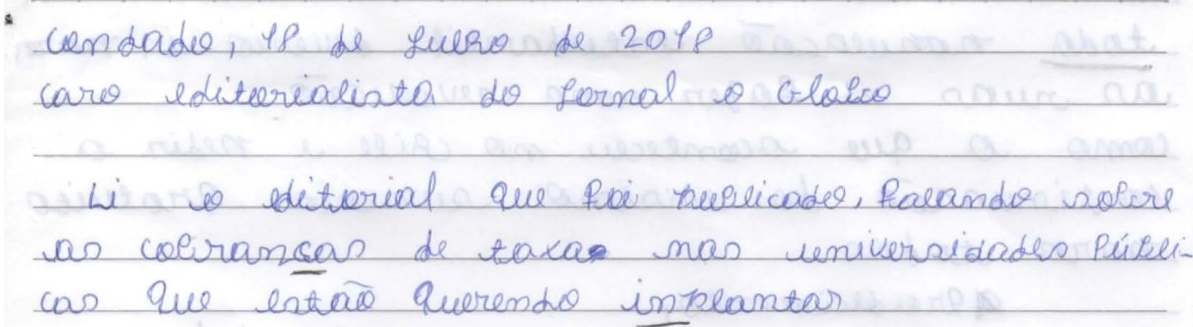 \\
\hline
\end{tabular}

Fonte: Dados da pesquisa de Oliveira (2019)

Cotejando as três versões da carta do leitor, podemos observar que, na primeira versão, o aluno inicia a carta sem se dirigir ao jornal ou ao editorialista, tampouco menciona o local e data, que são elementos constitutivos do contato. Ele apenas coloca um título, demonstrando já um certo distanciamento das orientações recebidas, em sala de aula, para a atividade de produção, sobre a estrutura básica do gênero em questão com base na proposta de Bezerra (2010). Podemos perceber ainda que, enquanto a primeira versão apresentou apenas um título, a segunda já apresenta a seção de contato mais adequando, uma vez que já manifesta a saudação ao editorialista do jornal. É, contudo, na terceira versão que o aluno constrói a seção de contato de forma mais elaborada, contemplando todos os elementos da estrutura do contato de uma carta do leitor, demostrando, assim, mais familiaridade com a estrutura do gênero.

Quanto ao primeiro parágrafo do texto, é possível perceber que o aluno constrói seu dizer de forma tímida, sem desenvolver uma ideia que sustente seu ponto de vista. Contu- do, podemos depreender que ele já sinaliza um posicionamento valorativo (BAKHTIN, 2016) de oposição à cobrança de mensalidade nas universidades públicas do Brasil, ponto de vista assumido no editorial ao qual o texto do aluno se propõe a responder. A sinalização dessa atitude de resposta não aparece sinalizada nessa primeira versão do texto. Nas demais versões, tanto na segunda como na terceira, se, por um lado, o aluno explicita mais claramente o seu diálogo com o editorial ${ }^{3}$ já publicado com o jornal, por outro lado, deixa menos evidente, em relação à primeira versão, o posicionamento assumido. Nesse caso, parece que a preocupação em atender a estrutura do gênero levou o aluno a se descuidar em relação à manifestação de seu posicionamento de forma mais explícita na introdução do texto.

3 Uma compreensão sobre a dimensão dialógica/ responsiva no gênero editorial, tomada, contudo, do ponto de vista do estudo da intertextualidade, pode ser melhor aprofundada a partir do trabalho de Santos (2013). 
Na nossa análise desses primeiros elementos de cada uma das três versões da carta, podemos perceber que o aluno revelou um progresso quanto ao domínio do gênero, numa demonstração de que ele não se fechou para escuta dos encaminhamentos, das orientações e intervenções da professora/pesquisadora. Com os espaços de interlocução criados, bem como o apoio em outros textos fornecidos, pela professora, como fontes de leituras/diálogos para desenvolver a atividade, constatamos que o dizer do aluno se enriqueceu com as situações dialógicas, entre aluno e textos, entre aluno e professora/pesquisadora, vivenciadas em sala de aula, revelando-se, assim, um "o encontro em que se solidarizam o refletir e o agir de seus sujeitos" (FREIRE, 2014, p. 109).

Compreendemos, nessa situação, e em tantas outras vivenciadas em sala de aula não reportadas aqui, o diálogo como "uma exigência substancial" (FREIRE, 2014, p. 109), não só para alterar/aperfeiçoar o projeto de dizer do aluno na produção escrita, mas também, e, principalmente, para contribuir com a formação do aluno como sujeito produtor de textos em construção, em constituição sempre inacabada.

A continuidade desse diálogo do aluno com os dizeres de seus outros, dos textos lidos/trabalhados em sala de aula e da professora/pesquisadora, pode ser observada no quadro a seguir, no qual temos os excertos correspondentes ao parágrafo de desenvolvimento da carta do leitor. Nesse parágrafo, pelo que podemos observar, o aluno procura deixar mais evidente o posicionamento assumido e os argumentos para sustentá-lo, senão vejamos:

Quadro 03 - Desenvolvimento da carta do leitor em cada versão da escrita

\begin{tabular}{|c|c|}
\hline $\begin{array}{c}\text { Primeira } \\
\text { versão }\end{array}$ & 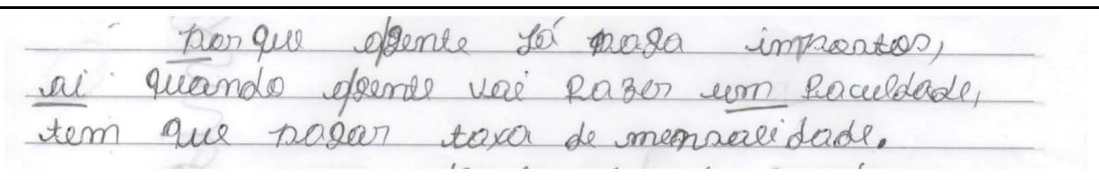 \\
\hline $\begin{array}{c}\text { Segunda } \\
\text { versão }\end{array}$ & 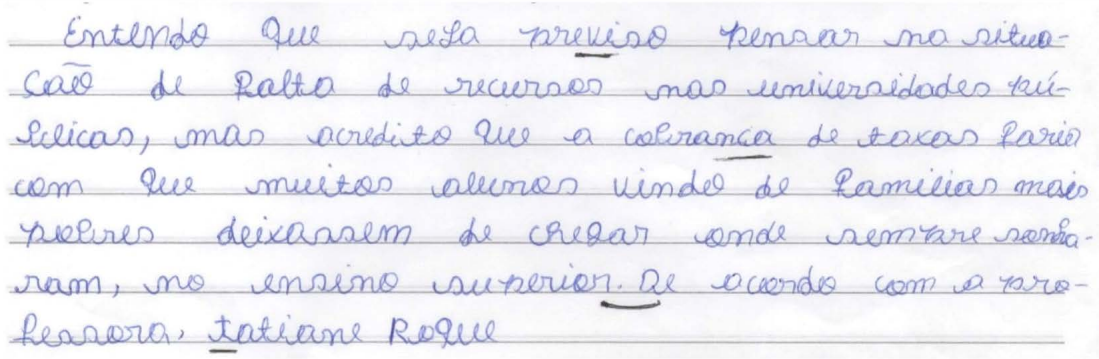 \\
\hline $\begin{array}{l}\text { Terceira } \\
\text { versão }\end{array}$ & 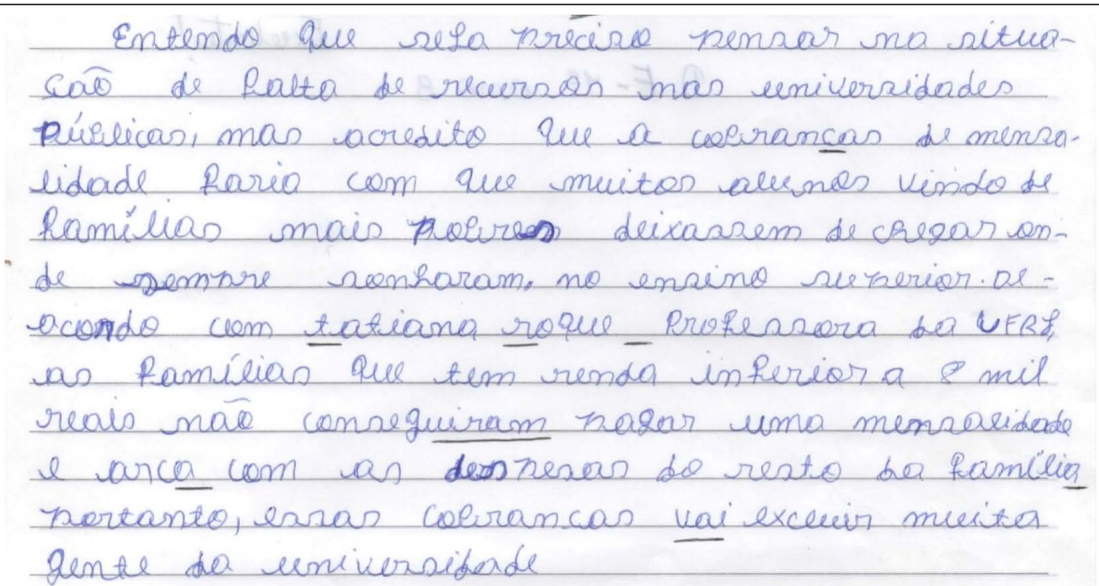 \\
\hline
\end{tabular}

Fonte: Dados da pesquisa de Oliveira (2019) 
A propósito do parágrafo de desenvolvimento, podemos observar claramente que a primeira versão apresenta uma espécie de justificativa para o posicionamento, que o aluno assume, contrário ao do editorial. Ele reporta ao argumento de que, como já paga "impostos", a população deve ter um retorno do estado sob a forma de serviços públicos, nesse caso, educação superior gratuita. Esse posicionamento assumido pelo aluno reflete atravessamentos de outros sujeitos, ratificando que as experiências discursivas de quem fala/escreve se constituem na interação com os enunciados de outrem (BAKHTIN, 2016).

Observamos, nessa versão, marcas de intervenção deixadas pela professora/pesquisadora, para que o aluno pudesse observar aspectos dos usos linguísticos que poderiam ser revistos e revisados numa nova etapa da escrita, firmando-se na convicção de que o texto não é um dado acabado, afinal, reflexo da atividade de um sujeito em processo de formação. Nesse sentido, ponderamos, a partir de Freire (1996), que a consciência da inconclusão do ser os torna sujeitos educáveis, na medida em que a educação é vista como um processo.

Beneficiando-se das intervenções da professora/pesquisadora, as versões dois e três da carta produzida pelo aluno apresentam, por sua vez, densidade textual e consistência argumentativa ampliadas. É possível demarcarmos os argumentos apresentados e recursos de autoridade (cita, de forma indireta, a fala de uma especialista na discussão, a professora Tatiana Roque, da UERJ) mobilizados para sustentar a defesa assumida no parágrafo de introdução, demonstrando, desse modo, amadurecimento nas leituras e na capacidade de transpô-las com mais desenvoltura na escrita.
A forma como o aluno se coloca nas duas últimas versões, mas sobretudo na terceira, deixa entrever a dedicação e o zelo com que se debruçou à feitura do texto no processo de reescrita. As discussões suscitadas no decorrer da escrita dessas versões transparecem compromisso com a atividade e um posicionamento mais elaborado. 0 fato de trazer, na terceira versão do texto, a voz de Tatiane Roque mobilizada de forma mais precisa e produtiva aponta não só que o aluno ampliou as leituras, como também que ele demonstrou capacidade de aperfeiçoar, em sua escrita, o gerenciamento de vozes reportadas como estratégia argumentativa para obter a adesão de seus possíveis interlocutores (ALVES, SOUZA, 2013).

Nesse processo de reconstrução da carta do leitor, é preciso considerar a atividade de reescrita, destacando a relevância das intervenções feitas pela professora/pesquisadora, tanto aquelas deixadas no próprio texto como aquelas apresentadas/discutidas oralmente em sala de aula, sem as quais o aluno teria dificuldades para produzir um texto adequado ao formato do gênero e condizente do ponto de vista da argumentatividade.

Como essencial nesse tipo de atividade, enfatizamos o que destaca Freire (1996), quando diz que o bom senso e a responsabilidade advertem o professor para orientar as atividades sem precisar ser autoritário. Nessa direção, compreendemos que a intervenção dialógica, sem cobranças e imposições, abre espaço não só para (re)construção do dizer, como também para que o aluno produza uma nova versão do seu texto sem a pressão de achar que o professor está ali somente para corrigir erros, mas, pelo contrário, para ser um parceiro, um interlocutor interessado no que ele tem a dizer.

No parágrafo de conclusão e na seção de 
despedida da carta do leitor produzida pelo aluno, podemos observar diferenças subs- tanciais no percurso de produção até a terceira versão, conforme vemos a seguir.

Quadro 04 - Conclusão e despedida da carta do leitor em cada versão da escrita

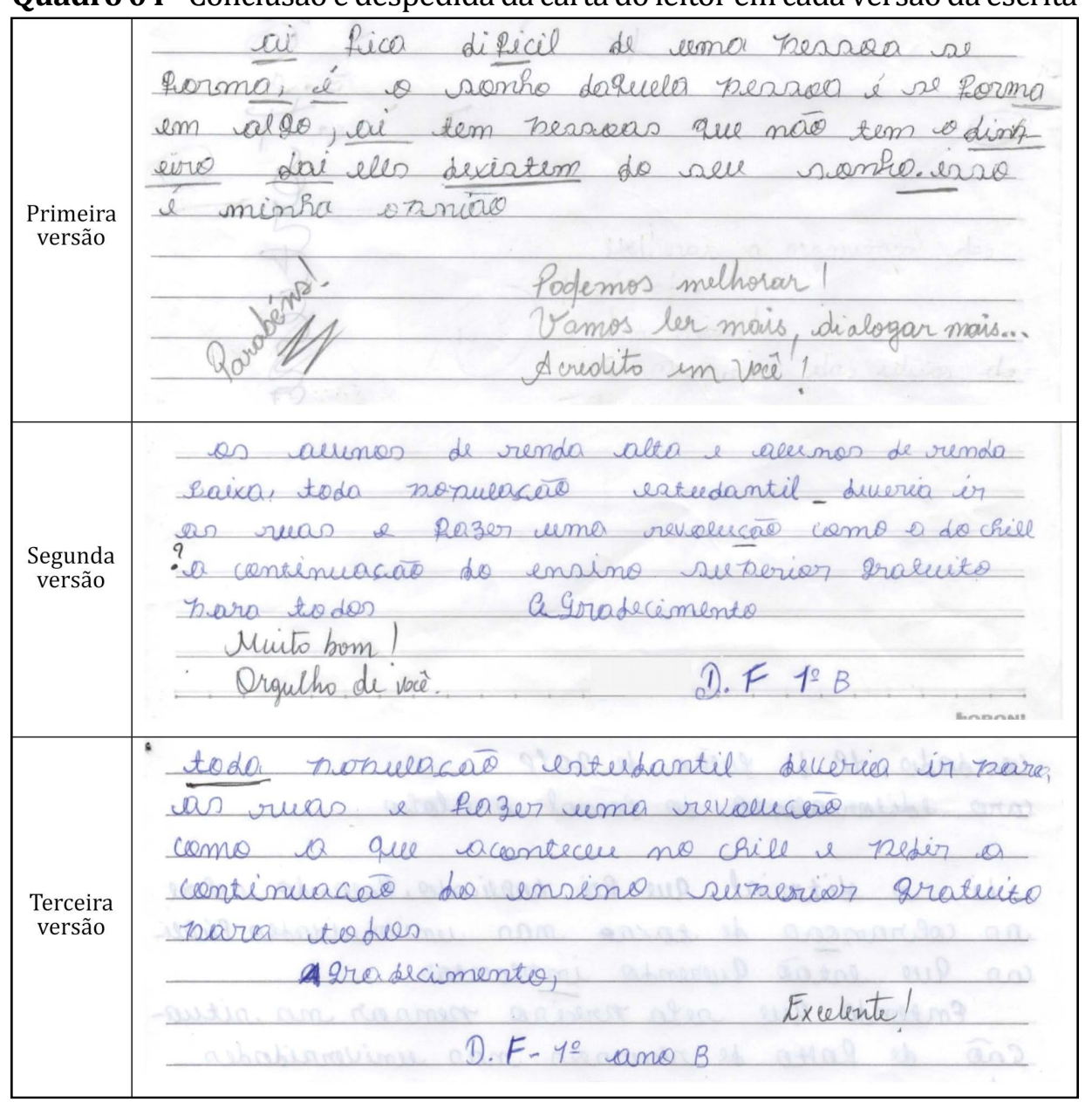

Fonte: Dados da pesquisa de Oliveira (2019)

Assim como nos demais elementos da carta, na conclusão e na despedida da carta do leitor do aluno, há diferenças acentuadas entre a primeira e as demais versões. É possível constatarmos, nas versões dois e três, uma mudança, quando comparamos com a primeira versão, na construção do dizer do aluno em sua conclusão. 0 aluno avança de uma mera opinião sobre a relação entre não ter dinheiro e ter condições de cursar o ensino superior a apresentação de uma proposta na defesa do engajamento da "população estudantil" na luta por um ensino superior gratuito para todos. Constatamos aí também que, diferentemente da primeira versão, as versões dois e três apresentam o elemento da despedida, quando vemos o termo "agradecimentos" e a assinatura do responsável pelo dito.

Considerando, pois, o olhar sobre a terceira versão, vemos como o aluno conseguiu demonstrar um progresso em relação ao domínio da forma e do conteúdo do gênero carta do leitor. Fica evidente que, as trocas interativas vivenciadas em sala de aula durante todas as etapas da intervenção (conforme descrição no quadro 1), fizeram com que o texto final apresentasse a estrutura do gênero esperada e revelasse uma visada argumentativa mais consistente e convincente, sinalizando, pois, o papel fundamental das relações dialógicas e escutas oportuni- 
zadas e da mediação docente na produção de textos concebida de forma processual.

No que se refere aos apontamentos feitos no texto do aluno é importante destacar que, nas primeiras versões, como podemos observar nos excertos selecionados para análise, a interação da professora/pesquisadora com o aluno se deu, potencialmente, de forma escrita no corpo do texto, e está demarcado pela presença de enunciados como Parabéns! Podemos melhorar! Muito bom! Orgulho de você. Essa postura se deu porque a professora/pesquisadora tinha como propósito maior criar um ambiente de motivação para que o aluno pudesse se dedicar à atividade de escrita, considerando que, conforme registros das notas de campo durante a fase que antecedeu a aplicação da intervenção, esse aluno raramente assistia as aulas de Língua portuguesa e, quando assistia, apresentava resistência para fazer as atividades propostas pela professora da disciplina.

Como podemos perceber, os apontamentos feitos pela professora/pesquisadora no final do texto do aluno se dão de forma textual-interativa, visto que não se limitam a apresentar equívocos linguísticos, mas contemplam também o incentivo ao trabalho de escrita, pois, nesse tipo de intervenção, o professor além de cobrar melhorias, pode fazer elogios ao texto do aluno (RUIZ, 2010). O encontro das palavras deixadas no texto, pela professora/pesquisadora, com as palavras do aluno, fez com que este construísse uma compreensão produtiva dos enunciados, postura que, muito possivelmente, foi determinante para o progresso dele no processo de construção e reconstrução de seu texto.

Compreendemos que essa postura da professora/pesquisadora dialoga com a concepção de um educador que entende sua prática, o saber-fazer docente, como prática de gente (FREIRE, 1996). Além disso, dialogando com Bakhtin (2016), compreendemos que essa relação não só contribui para a constituição do aluno/produtor de texto, como corrobora para a construção do sujeito social, que constitui e que é constituído pelo outro.

As análises aqui realizadas nos permitem provocar reflexões acerca da prática docente, pois um sujeito que não se reconhece como (in)acabado, que não está aberto ao diálogo, à escuta, que vê o aluno como coisa e não como gente, que não reflete sobre sua prática, dificilmente irá conseguir fazer com que o aluno se sinta motivado a participar das aulas, a realizar as atividades e a ter experiências de formação e aprendizado produtivas e significativas. Compreendemos, pois, que momentos de reflexão sobre a atuação de todos os sujeitos envolvidos na prática social, dentro e fora da escola (SILVA, 2014), abre caminhos para pensarmos estratégias pedagógicas que possibilitem uma atuação crítica e transformadora de nossos alunos em suas práticas sociais.

\section{Palavras inacabadas}

Nosso propósito, neste trabalho, foi analisar como a mediação do professor e as vivências dialógicas podem propiciar um evento de interlocução professor-aluno autêntico e efetivo no espaço da aula de produção textual e colaborar com a constituição do ser/ sujeito produtor de texto. Nesse sentido, buscamos examinar relações de interação entre professor e aluno durante uma atividade de produção de textos em aulas de língua portuguesa do primeiro ano do ensino médio.

Dialogando especialmente com ideias de Freire (1986, 1996, 2014) e de Bakhtin $(2016,2017)$ e apoiando-se em um estudo 
de natureza qualitativa e interpretativa, realizamos análise de relações de interação entre professor e aluno durante uma atividade de produção de textos em aulas de língua portuguesa do ensino médio.

A análise realizada aponta que a postura interativa, dialógica da professora/pesquisadora durante todo o processo de escrita/ reescrita e nas etapas que antecederam este processo, contribuiu para o progresso do aluno em relação ao domínio da forma e do conteúdo do gênero carta do leitor. A análise aponta ainda que as trocas interativas vivenciadas, durante a atividade interventiva, possibilitaram que o texto final apresentasse a estrutura do gênero esperada e revelasse uma visada argumentativa mais consistente e convincente, sinalizando, pois, o papel fundamental das relações dialógicas e escutas oportunizadas e da mediação docente na produção de textos e na formação de um sujeito produtor de textos.

Nesse sentido, é importante assinalar o fato de a professora/pesquisadora não reproduzir uma prática de solicitar a produção de textos na escola apenas para cumprimento de uma nota, mas, antes de tudo, assumindo o compromisso com a produção de textos como um processo interlocutivo autêntico, concebendo o aluno como um sujeito produtor (in)acabado, que se constrói e se reconstrói nos momentos de idas e vindas, de escritas e reescritas, em novas leituras/compreensões, nas relações dialógicas, na escuta do outro.

Assim, esperamos que a experiência aqui reportada e a leitura que realizamos neste trabalho provoquem a resposta de outros pesquisadores/estudiosos, no sentido de que eles possam explorar outras vivências, outros sujeitos e outras experiências de sala de aula, para que, desse modo, possamos mobilizar mais pesquisadores e professores em torno de práticas mais dialógicas e engajadas com uma formação mais crítica e comprometida com a atuação transformadora dos sujeitos em suas práticas sociais.

\section{Referências}

ALVES, M. L; SOUZA, G. S. de. Na tensão de vozes, a (re)velação de imagens: o ethos de estudantes de letras em relatórios de estágio. Diálogo das Letras, v. 02, n. 01, p. 125 - 146, jan./jun. 2013.

ANTUNES, I. Análise de textos: fundamentos e práticas. São Paulo: Parábola Editorial, 2010.

ANTUNES, I. Língua, texto e ensino: outra escola possível. São Paulo: Parábola Editorial, 2009.

AMORIM, M. As ciências humanas e sua especificidade discursiva. In: RODRIGUES, R. H.; PEREIRA, R. A. (org.). Estudos dialógicos da linguagem e pesquisas em Linguística Aplicada. São Carlos: Pedro \& João Editores, 2016, p. 17-45.

BAKHTIN, M. Os gêneros do discurso. Organização, tradução, posfácio e notas de Paulo Bezerra. 1.ed.São Paulo: Editora 34, 2016.

BAKHTIN, M. Notas sobre literatura, cultura e ciências humanas. Organização, tradução, posfácio e notas de Paulo Bezerra. 1. ed. São Paulo: Editora 34, 2017.

BAKHTIN, M. Reformulação do livro sobre Dostoiévski. In: BAKHTIN, M. Estética da criação verbal: introdução e tradução do russo Paulo Bezerra. 6. ed. São Paulo: Editora WMF Martins Fontes, 2011, p. 336- 357.

BESSA, J. C. R. Dialogismo e construção da voz autoral na escrita do texto científico de jovens pesquisadores. 2016, $385 \mathrm{f}$. Tese (Doutorado em Linguística e Língua Portuguesa) - Universidade Estadual Paulista "Júlio de Mesquita Filho", Faculdade de Ciências e Letras, Araraquara, 2016.

BEZERRA, M. A. Ensino de língua portuguesa e contextos teóricos- metodológicos. In: DIONISIO, A. P; MACHADO, A. R; BEZERRA, M. A. (org.). Gêneros textuais \& ensino. São Paulo: Parábola Editorial, 2010, p. 39-50.

FREIRE, P. Pedagogia do oprimido. 56. ed. Rio de Janeiro: Paz e Terra, 2014. 
FREIRE, P. Pedagogia da esperança: um reencontro com a pedagogia do oprimido. 7. ed. São Paulo: Paz e Terra, 2000.

FREIRE, P. Pedagogia da autonomia: saberes necessários à prática educativa. São Paulo: Paz e Terra, 1996.

FREIRE, P. Educação como prática da liberdade. 17.ed. Rio de Janeiro: Paz e Terra,1986

GERALDI, J. W. Passando em revista ideias sobre o ensino de língua portuguesa: uma entrevista com João Wanderley Geraldi. Entrevista realizada por Lívia Suassuna e Rosângela Alves dos Santos Bernardino. Diálogo das Letras, v. 06, n. 01, p. 490-496, jan./jun. 2017.

GERALDI, J. W. A aula como acontecimento. 2.ed. São Carlos. Pedro \& João Editores, 2015.

GERALDI, J. W. Portos de passagem. 5. ed. São Paulo: Editora WMF Martins Fontes, 2013.

GERALDI, J. W. Concepções de linguagem e ensino de português. In: GERALDI, J. W. (org.). 0 texto na sala de Aula. 4. ed. São Paulo, Ática, 2012, p. 39-45.

GERALDI, J. W. Paulo Freire e Mikhail Bakhtin: o encontro que não houve. In: CORTESÃO, L. et al. Diálogos através de Paulo Freire. Porto: Edição Instituto Paulo Freire de Portugal e Centro de Recursos Paulo Freire da FPCE, 2003/2004, p.37-52.

LOPES-ROSSI. M. A. G. Gêneros discursivos no ensino de leitura e produção de textos. In. KARWOSKI, A. M; GAYDECZKA, B; BRITO, K. S. (org.). Gêneros textuais: reflexões e ensino. 4. ed. São Paulo: Parábola Editorial, 2011, p. 69-82.

MENDONÇA, M. C. A produção textual na esfe- ra escolar: considerações sobre a "escrita como trabalho". Diálogo das Letras, v. 8, n. 1, p. 3-15, jan./abr. 2019.

MORETTO, M. Produção de textos em sala de aula: momento de interação e diálogo. Jundiaí: Paco editorial, 2013.

MOURA; MIOTELLO, V: A escuta da palavra alheia. In: RODRIGUES, R. H; ACOSTA, R. (org.). Estudos dialógicos da linguagem e pesquisas em linguística aplicada. São Carlos: Pedro \& João editores, 2016, p. 129- 140.

OLIVEIRA, J. A. Produção textual argumentativa na sala de aula: do editorial à carta do leitor. 2019, 179f. Dissertação (Mestrado em Ensino) - Universidade do Estado do Rio Grande do Norte, Campus de Pau dos Ferros, Pau dos Ferros, 2019.

ROJO, R; BARBOSA. J. Hipermodernidade, multiletramentos e gêneros discursivos. 1.ed. São Paulo: Parábola Editorial, 2015.

RUIZ, E. D. Como corrigir redações na escola. 2. ed. São Paulo: Contexto, 2010.

SANTOS, E, P. A intertextualidade na construção argumentativa do artigo de opinião. Diálogo das Letras, Pau dos Ferros, v. 02, n. 01, p. 300 314, jan./jun. 2013.

SILVA, S. L. Algumas considerações sobre memorial de leitura e a constituição do ethos discursivo na formação inicial do professor de língua portuguesa. Diálogo das Letras, v. 03, n. 02, p. 05-22, jul./dez. 2014.

Recebido em: 11/05/2020

Aceito em: 16/06/2020 